\title{
Ni Substituted MgMn Nanoferrites as Antibacterial Agent for Biotextile Application
}

\author{
M. S. Revathy, S. R. Chitra, R. Suman, S. Shenbagavalli, S. Jeyavijayan, T. Theivashanthi
}

\begin{abstract}
Biological aspects of nanoferrite incorporation is growing in demand in textile industries. In this regard the present study focuses on the synthesis of nanoferrite with Nickel substitution by Coprecipitation route. Structural studies of the nanoferrites was analyzed using $X$-ray diffraction. The chemical analyses determined by TEM, was in good agreement with that of $X R D$ analysis. Thermal analysis by TG/DTA inferred that nanoferrites were thermally stable due to Ni dopants added with the compounds. $\mathrm{MgMnNiFe}_{2} \mathrm{O}_{4}$ nanoferrites on cotton fabrics was subjected antibacterial assay on various pathogenic microorganism and exhibits the zone of inhibition. The fabricated nanoferrites on cotton fabrics showed great durability evidenced by their antibacterial activities even after 20 washing cycles. Hence, the functionalized cotton fabrics could be used as a potential antibacterial agent.
\end{abstract}

Keywords: Antibacterial activities, Co-precipitation, Ferrites, TEM, TGA XRD.

\section{INTRODUCTION}

Ferrite compounds has generic formula $\mathrm{XFe}_{2} \mathrm{O}_{4}$ where $\mathrm{X}$ being a divalent metal ion $\left(\mathrm{Fe}_{2+}, \mathrm{Ni}_{2+}, \mathrm{Mg}_{2+}, \mathrm{Mn}_{2+}, \mathrm{Zn} 2+, \mathrm{Cu} 2+\right)$. Nanoparticulate ferrites has credible properties such as uniform size of the particle and narrow size distribution, non-toxic, antimicrobial, biocompatibility, biodegradability and chemical inertness. These properties makes it a desirable candidate for multifarious applications like drug delivery, ferrofluids, medical imaging, magnetic data storage, sensors, catalytic, microwave applications [1,2]. Recent investigated literatures of nanoferrite particle, claims that it can be applied in biomedical field due to its antibacterial properties.

For the preparation of the identified ferrite compound coprecipitation liquid phase route is best suited due to desirable stoichiometry, process done at low temperature, rapid, doesn't require sophisticated instruments.

Herein we present, substitution of $\mathrm{Ni}^{2+}$ on $\mathrm{Mg}-\mathrm{Mn}$ ferrites using simple technique of coprecipitation. The structural

Revised Manuscript Received on December 18, 2019

* Correspondence Author

M. S. Revathy*, Physics, Kalasalingam Academy of Research and Education, Krishnankoil,Virudhunagar, India. Email: revz.vijay@gmail.com

S. R .Chitra*, Physics, Thiagarajar College of Engineering, Madurai, India. Email: jaicitra@gmail.com

R.Suman, Chemistry, Francis Xavier Engineering College.

Gmail : chesuman@gmail.com shenbaphy321@gmail.com

S. Jeyaviajyan, Physics, Kalasalingam Academy of Research and jeyavijayan@gmail.com

T. Theivashanthi, Physics, Kalasalingam Academy of Research and Education, Krishnankoil, Virudhunagar, India. Email: theivasanthi@gmail.com
S. Shenbagavalli, Physics, Kalasalingam Academy of Research and Education, Krishnankoil, Virudhunagar, India. Email: Education, Krishnankoil,Virudhunagar, India. Email

characterization was performed with XRD and the effect of $\mathrm{Ni}^{2+}$ ions on morphological and thermal properties for the development of antimicrobial textiles was analyzed with SEM and TGA respectively.

\section{EXPERIMENTAL}

The study seeks to address, a series of ferrites $\mathrm{Mg}_{0.40} \mathrm{Mn}_{0.60-\mathrm{x}} \mathrm{Ni}_{\mathrm{x}} \mathrm{Fe}_{2} \mathrm{O}_{4}[0.00 \leq \mathrm{x} \leq 0.45]$ prepared with the appropriate stoichiometric amounts of $\mathrm{Ni}$ using chemical co-precipitation method owing due to its relative easy reaction process, good quality control over the particle dimension and shape[3].

The chosen precursors $\mathrm{MgSO}_{4} \cdot 7 \mathrm{H}_{2} \mathrm{O}, \quad \mathrm{MnSO}_{4} \cdot \mathrm{H}_{2} \mathrm{O}$, $\mathrm{NiSO}_{4} 6 \mathrm{H}_{2} \mathrm{O}$ and $\mathrm{FeCl}_{3}(0.2 \mathrm{M})$ for the study were made into aqueous solutions in $100 \mathrm{ml} \mathrm{DM(Demineralized)} \mathrm{water.} \mathrm{The}$ alkaline $\mathrm{NaOH}$ of $3 \mathrm{M}$ concentration was added gradually to the former aqueous bath. Under constant stirring, the temperature was optimized to $70{ }^{\circ} \mathrm{C}$ waited for obtaining a clear solution. The settled precipitate was carefully collected and was dried. Finally, ultrafine particles of $\mathrm{Mg} 0.40 \mathrm{Mn} 0.60-\mathrm{xNixFe} 2 \mathrm{O} 4$ were prepared. Similar process was repeated for the different concentrations of $\mathrm{x}=0,0.15$, $0.25,0.35$ and 0.45 .

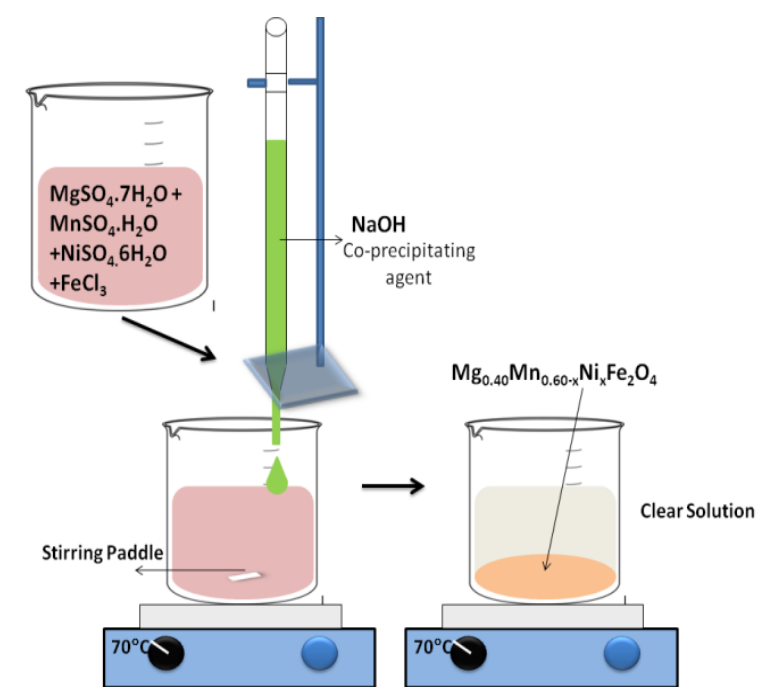

Fig.1. Schematic illustration of synthesis process

Steps involved in the synthesis are co-precipitation and ferritization. Solid hydroxides of metals in the form of nanoferrites were obtained by the co-precipitation of metal cations in alkaline medium. Solid solution of metal hydroxides was transformed to complex nickel substituted nanoferrites when subjected to heating in the alkaline medium. 


\section{RESULTS AND DISCUSSION}

\section{A.Structural Studies}

For the structural characterization and formation of single spinel phase, all the samples were characterized by XRD analysis using Philips X'pert PROPANalytic X-ray diffractometer which uses $\mathrm{CuK} \alpha$ as a radiation source, was used to confirm the formation of spinel phase, operated maximum resolution. TABLE- I yields the parameters values of $\mathrm{Mg}_{0.40} \mathrm{Mn}_{0.60-\mathrm{x}} \mathrm{Ni}_{\mathrm{x}} \mathrm{Fe}_{2} \mathrm{O}_{4}$ for different concentrations $(x)$. The measured density as well as X-ray density of the prepared samples was estimated using the relation,

$$
\begin{gathered}
\rho_{m}=\frac{m}{\mathrm{~s}^{2} h} \\
\rho_{x}=\frac{a^{3}}{}
\end{gathered}
$$

where $\mathrm{m}$, the mass; $\mathrm{r}$, the radius; $\mathrm{h}$, height; $\mathrm{M}$, the molecular weight of the samples; $\mathrm{N}$, the Avogadro's number and a, the lattice constant.

In the compositions of the nanoferrite, there was a notable observance of decrement in the values of lattice parameters with the reduction in $\mathrm{Mn}$ concentration. Also, there was an increment in $\mathrm{Ni}$ concentration. Likewise, average crystallite size was found to depend on $\mathrm{Mn}(x)$ concentration. The value shows decrement with decrease in the concentration of $\mathrm{Mn}$ due to the fact that, larger $\mathrm{Mn}$ ionic radius could be replaced by smaller $\mathrm{Ni}$ ionic radius (i.e) larger metal ions might have been substituted with relatively smaller metal ions. This observation was in good agreement with other research reports[4].

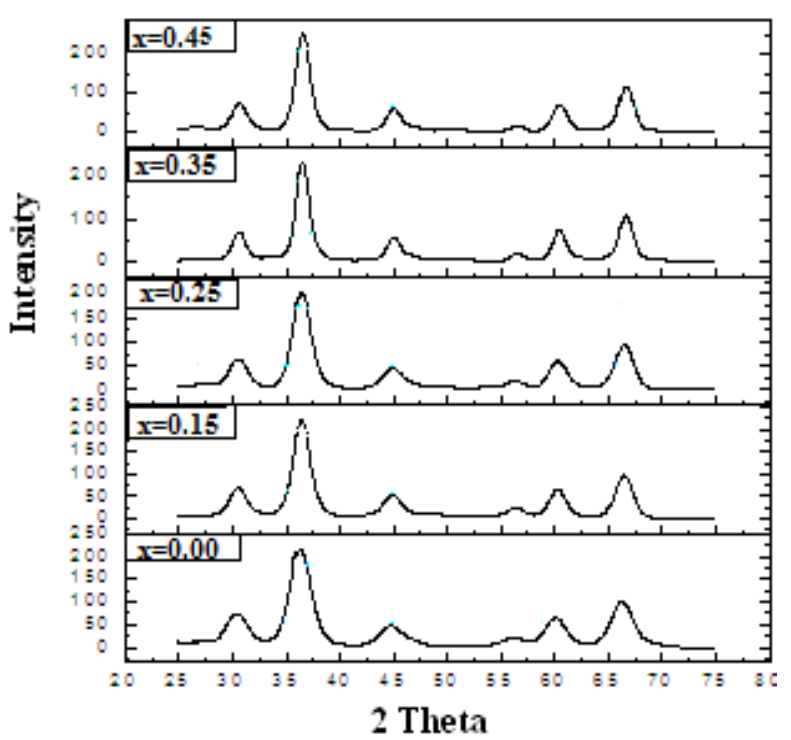

Fig. 1. Typical XRD patterns of $\mathrm{Mg}_{0.40} \mathrm{Mn}_{0.60-\mathrm{x}} \mathrm{Ni}_{\mathrm{x}} \mathrm{Fe}_{2} \mathrm{O}_{4}$ $(0.00 \leq \mathrm{x} \leq 0.45)$ nanoferrites

Table- I: Lattice parameters of the prepared nanoferrites

\begin{tabular}{|c|c|c|c|c|c|}
\hline \multirow{2}{*}{ Parameters } & \multicolumn{5}{|c|}{ Compositions of x } \\
\cline { 2 - 6 } & $\mathbf{0 . 0 0}$ & $\mathbf{0 . 1 5}$ & $\mathbf{0 . 2 5}$ & $\mathbf{0 . 3 5}$ & $\mathbf{0 . 4 5}$ \\
\hline $\mathrm{D}(\mathrm{nm})$ & 9.52 & 14.25 & 14.12 & 9.88 & 9.50 \\
\hline $\mathrm{a}(\mathrm{A})$ & 8.415 & 8.433 & 8.429 & 8.4209 & 8.402 \\
\hline $\mathrm{V}(\mathrm{A})^{3}$ & 595 & 599 & 598.12 & 596 & 594 \\
\hline $\begin{array}{c}\rho_{\mathrm{x}}(\mathrm{X}-\mathrm{Ray} \\
\text { Density) }\end{array}$ & 5.85 & 5.81 & 5.814 & 5.838 & 5.84 \\
\hline $\begin{array}{c}\rho_{\mathrm{m}} \\
\left(\begin{array}{c}\text { Measured } \\
\text { Density) }\end{array}\right.\end{array}$ & 4.41 & 4.39 & 4.397 & 4.41 & 4.42 \\
\hline
\end{tabular}

\section{B. Morphological Studies}

Morphological studies of TEM explained the complete picture of the nanoferrites and are shown in Fig.2.

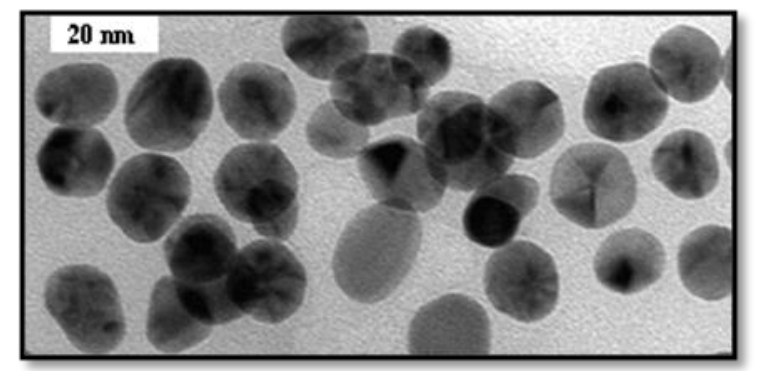

Fig. 2. TEM image for $\mathrm{Mg}_{0.40} \mathrm{Mn}_{0.60-\mathrm{x}} \mathrm{Ni}_{\mathrm{x}} \mathrm{Fe}_{2} \mathrm{O}_{4}$ nanoferrites with the compositions of $\mathrm{x}=\mathbf{0 . 4 5}$

In the image there were uniform distribution and less agglomeration of homogenous spherical particles with size of $20 \mathrm{~nm}$ and in line with the agreement of XRD analysis.

\section{C.Thermal Analyses}

TGA/DTA spectra have been recorded in temperature range from 25 to $800{ }^{\circ} \mathrm{C}$ at a heating rate of $10^{\circ} \mathrm{C}$ per min using Thermo-Gravimetric Analyzer with Differential thermal analyzer (SII Nanotechnology Inc., Japan, EXSTAR 6000 TG/DTA). Thermogravimetry is an extensively used tool for thermal stability, decomposition temperature, temperature of desorption and drying, oxidative stability determination of the synthesized product[5]. Usually, powder samples ranging from $8 \mathrm{mg}$ to $10 \mathrm{mg}$ were weighed and heated from 50 to $800{ }^{\circ} \mathrm{C}$. During this process temperature difference and weight loss were recorded as a function of temperature.

The TG/DTA/DTG plots for the synthesized ferrites are shown in Fig. 3. From TG analysis we observed that all the samples have been observed to possess weight loss in four steps. The very first weight loss around $100{ }^{\circ} \mathrm{C}$ could be attributed to initial dehydration, loss of mass is due to vapourization of surface water molecules and more loss of mass around $250{ }^{\circ} \mathrm{C}$ due to vaporization of trapped water molecules.

The temperatures of respective weight losses have been observed to increase with increasing $\mathrm{Ni}$ concentration. In DTA thermogram, the weight loss below $150{ }^{\circ} \mathrm{C}$ is linked with an endothermic DTA peak occurred due to absorbed water loss. The first exothermic peak at around $250{ }^{\circ} \mathrm{C}$ in the DTA curve, go together with a very large weight loss (around $25 \%$ ) in the TGA thermogram. During this period small weight loss occurred in the temperature range $250^{\circ} \mathrm{C}$ to 500 ${ }^{\circ} \mathrm{C}$ along the second DTA exothermic peak, which is probably due to the removal of excess water (if any). Beyond this temperature the material began to degrade. Theoretical weight loss, \% and Experimental weight loss, \% of the prepared samples were calculated and tabulated in Table- II. 

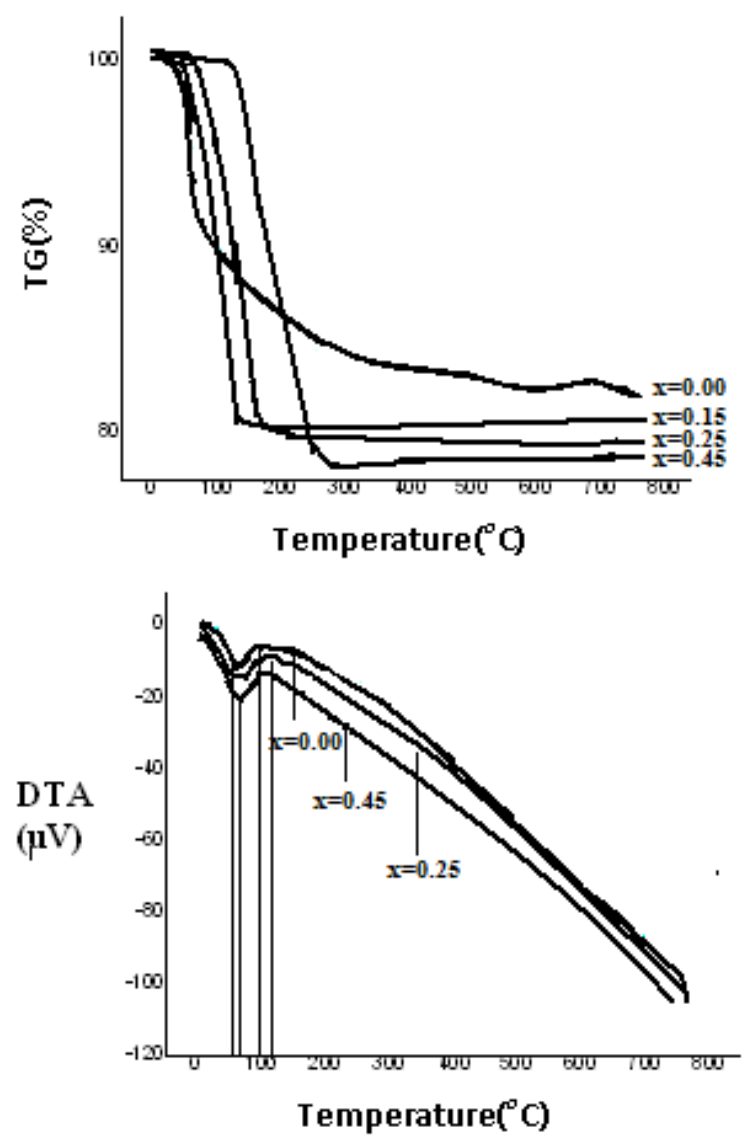

Fig. 3. Typical TGA/DTA profiles of the samples

Table- II: Theoretical Weight Loss, \% And Experimental Weight Loss, \% Of The Prepared Samples

\begin{tabular}{|c|c|c|c|}
\hline $\boldsymbol{x}$ & $\begin{array}{c}\text { Temperature of } \\
\text { dehydration }\end{array}$ & $\begin{array}{c}\text { Theor. weight } \\
\text { loss, \% }\end{array}$ & $\begin{array}{c}\text { Experimental } \\
\text { weight loss, \% }\end{array}$ \\
\hline 0.00 & 90 & 7.47 & 7 \\
\hline 0.15 & 120 & 20.12 & 19.5 \\
\hline 0.25 & 180 & 21.8 & 20.5 \\
\hline 0.35 & 210 & 22.3 & 21.5 \\
\hline 0.45 & 250 & 22.6 & 22.25 \\
\hline
\end{tabular}

\section{D.Antibacterial assay}

The antibacterial activities of the prepared nanoferrites of dissimilar concentration were tested against the pathogens like Pseudomonas fluorescens, Proteus mirablis, Staphylococcus aureus, Klebsiella pneumoniae, Escherichia coli and Enterobacter aerogenes were inoculated in nutrient broth and kept in shaker for overnight incubation. Antibacterial activities were evaluated by measuring inhibition zones. Different concentrations of synthesized nanoferrites were loaded on cotton fabrics to study their antibacterial activities by agar based diffusion method. The loaded plates were incubated at $40{ }^{\circ} \mathrm{C}$ for 24 hours and inhibition zones developed around the discs was measured[6]. The nanoferrites treated on cotton fabrics were evaluated for their antibacterial activities before and after washing.

The test organisms, bacterial strains are Proteus mirablis [MTCC 3310], Staphylococcus aureus [MTCC 87], Enterococcus aerogenes [MTCC 111], Escherichia coli [MTCC 64], Klebsiella pneumoniae [MTCC 39], Pseudomonas fluorescens [MTCC 103] were procured from
IMTECH(Institute of Microbial Technology). Agar based diffusion method was carried out for anti-bacterial evaluation [7].

Table- III:Antibacterial activities of $\mathrm{MgMnNiFe}_{2} \mathrm{O}_{4}$ ferrite particles

\begin{tabular}{|c|c|c|c|c|}
\hline \multirow{2}{*}{ Organism } & \multicolumn{4}{|c|}{$\begin{array}{c}\text { Antibacterial activities (Zone of } \\
\text { inhibition in cm) }\end{array}$} \\
\cline { 2 - 5 } & $\begin{array}{c}\mathbf{2 5} \\
\boldsymbol{\mu g} / \mathbf{m l}\end{array}$ & $\begin{array}{c}\mathbf{5 0} \\
\boldsymbol{\mu g} / \mathbf{m l}\end{array}$ & $\begin{array}{c}\mathbf{7 5} \\
\mathbf{\mu g} / \mathbf{m l}\end{array}$ & $\begin{array}{c}\mathbf{1 0 0} \\
\boldsymbol{\mu g} / \mathbf{m l}\end{array}$ \\
\hline Proteus mirablis & - & 1.3 & 1.8 & 1.9 \\
\hline Staphylococcus aureus & - & 1.8 & 1.9 & 2.0 \\
\hline Enterococcus aerogenes & - & 1.6 & 1.7 & 2.4 \\
\hline Escherichia coli & - & 1.4 & 1.8 & 2.2 \\
\hline Klebsiella pneumoniae & - & 1.0 & 1.4 & 1.7 \\
\hline Pseudomonas fluorescens & - & 0.8 & 1.5 & 1.8 \\
\hline
\end{tabular}

- Recording of Zone of inhibition

Nanoferrites treated on cotton fabrics $(10 \mathrm{~mm} \times 10 \mathrm{~mm})$ were used. Steps involved for observation

1. Selection of bacterial stains (Gram positive : Staphylococcus aureus, Bacillus subtilis, Streptococcus sp. and Gram negative: Escherichia coli, Proteus mirablis, Klebsiella pneumonia)

2. Inoculation of bacterial pathogens in sterile nutrient broth.

3. Incubation of plates for 24 hours at $40{ }^{\circ} \mathrm{C}$

4. Recording of zone of inhibition around the fabrics.

\section{E. Antibacterial reduction \% (After washing)}

The nanoferrites treated on cotton fabrics were evaluated for their antibacterial activities before and after washing. $\mathrm{MgMnNiFe}_{2} \mathrm{O}_{4}$ particles coated and uncoated fabrics were taken individually in $3000 \mathrm{ml}$ sterile Schott Duran flasks and $1 \mathrm{ml}$ of overnight grown bacterial suspension was added.

Percentage reduction(PR) of each bacterium was estimated by the formulae:

$$
P R=\frac{[100[B-A]]}{B}
$$

where $\mathrm{A}$ and $\mathrm{B}$ are the total number of bacteria recovered from nanoferrites untreated and treated on fabrics respectively. $\mathrm{MgMnNiFe}_{2} \mathrm{O}_{4}$ nanoferrites wash durability treated on cotton fabrics was assessed after 5, 10 and 15 wash cycles using neutral soap (5\% Hiclean, HiMedia) at $40 \pm 2^{\circ} \mathrm{C}$ for 45 minutes with a material to liquid ratio of 1:50. Then subsequent rinsing and drying was repeated to a maximum of 15 wash cycles. The prepared nanoferrites showed greater inhibitory activity against all the experimental strains with $50 \mu \mathrm{g} / \mathrm{ml}$ and above concentrations are shown in Fig. 4 and Table- III. 
Table- IV: Effect of wash cycles on antibacterial activities of cotton fabrics loaded with particles

\begin{tabular}{|c|c|c|c|c|}
\hline \multirow[t]{2}{*}{ Organism } & \multicolumn{4}{|c|}{ Antibacterial activity (Reduction percentage \%) } \\
\hline & Before washing & After 5 washes & After 10 washes & After 15 washes \\
\hline Proteus mirablis & 99.81 & 98.63 & 96.13 & 94.32 \\
\hline Staphylococcus aureus & 99.52 & 98.54 & 96.11 & 94.43 \\
\hline Enterococcus aerogenes & 99.78 & 98.85 & 96.34 & 94.87 \\
\hline Escherichia coli & 99.37 & 98.78 & 96.14 & 95.53 \\
\hline Klebsiella pneumonia & 99.45 & 98.76 & 96.17 & 95.02 \\
\hline Pseudomonas fluorescens & 99.12 & 97.76 & 95.23 & 92.98 \\
\hline
\end{tabular}

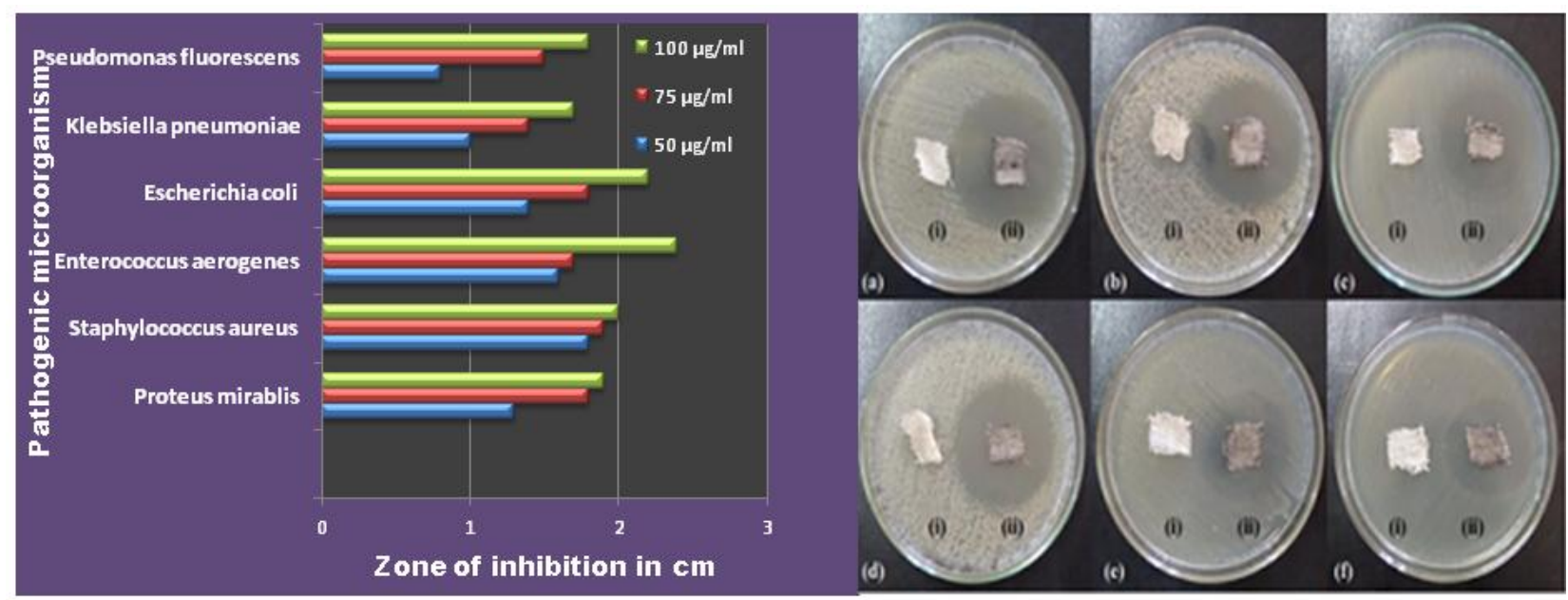

Fig. 4. Antibacterial activities on cotton fabrics with coated and uncoated particles (I) $25 \mu \mathrm{g} / \mathrm{ml}$; (II) $50 \mu \mathrm{g} / \mathrm{ml}$; (a) Proteus mirablis, (b) Staphylococcus aureus, (c) Enterococcus aerogenes, (d) Escherichia coli,(e) Klebsiella pneumoniae, (f) Pseudomonas fluorescens

It is obvious from the Table- III that antibacterial activity of the zone of inhibition $=100 \mu \mathrm{g} / \mathrm{ml}$ is found to be higher in Escherichia coli and Enterococcus aerogenes than those of other concentrations. However lesser activity is recorded on Pseudomonas fluorescens. The antibacterial properties of $\mathrm{MgMnNiFe}_{2} \mathrm{O}_{4}$ nanoferrites treated on cotton fabrics were evaluated against selected Gram positive and Gram negative bacteria.

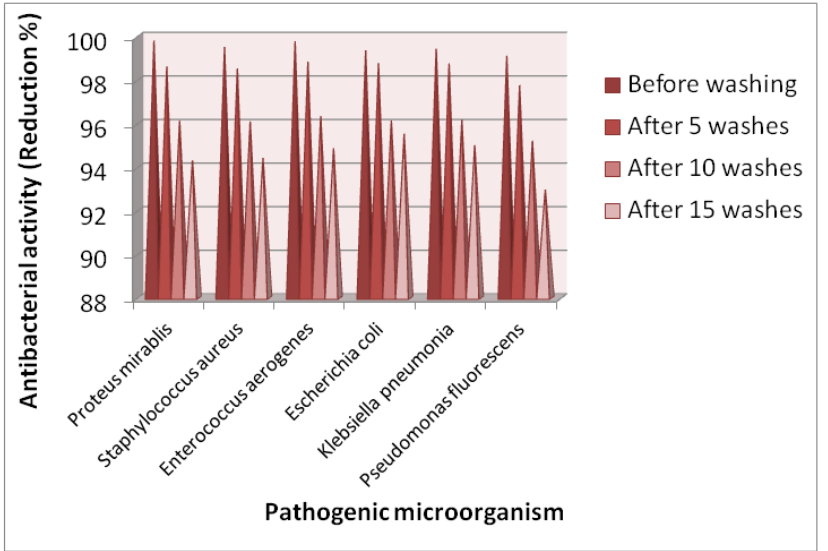

Fig. 5. Antibacterial responses in effect of wash cycles of cotton fabrics loaded with particles

The antibacterial efficiency of the prepared nanoferrites treated on cotton fabrics was studied using agar diffusion assay and the results were shown in Fig. 5 and TABLE- IV. Furthermore preceding studies have indicated that the smaller $\mathrm{MgMnNiFe}_{2} \mathrm{O}_{4}$ particle size, the greater the efficacy in inhibiting the growth of bacteria than other's reports[8,9]. conversely nanoferrites of $\mathrm{MgMnNiFe}_{2} \mathrm{O}_{4}$ were formerly reported to act both as bactericidal agent and also bacteriostatic agent possibly thereby limiting their biomedical use.

\section{CONCLUSION}

The results on the investigations of the nanoferrites demonstrate that $\mathrm{Ni}$ substituted $\mathrm{MgMn}$ nanoferrite particles inhibited the growth of bacteria at very low concentrations. The influence of $\mathrm{MgMnNiFe}_{2} \mathrm{O}_{4}$ nanoferrites and morphology of the nanostructure is significant for the antimicrobial activity of the prepared particles which is an important aspect for textile industries. Thus, the application of these nanoferrites as antibacterial agent will be very precious for biomedical and industrial applications.

\section{REFERENCES}

1. K. Kluchova, R. Zboril, J.Tucek, M.Pecova, L.Zajoncova, I.Safarik, M.Mashlan, I. Markova,D.Jancik, M. Sebela, H.Bartonkova, V.Bellesi, P. Novak, D. Petridis, "Superparamagnetic maghemite nanoparticles from solid-state synthesis - Their functionalization towards peroral MRI contrast agent and magnetic carrier for tryps in immobilization,' Biomaterials, vol.30, no.15, 2009, pp. 2855-2863.

2. K. Vishal Chakradhary, Azizurrahaman Ansari, M. J Akhtar, "Synthesis and characterization of nickel cobalt ferrite nanoparticles via heat treatment method," Advance Materials Proceedings, vol.1, no. 1, 2016 , pp. 76-80.

3. R. Dehghan, S.A. Seyyed Ebrahimi, Badiei, "Investigation of the effective parameters on the synthesis of Ni-ferrite nanocrystalline powders by co-precipitation method," J. of Non Crystalline Solids, vol. 354, 2008, pp.5186-5188. 
4. Waldron, R.D, Infrared Spectra of Ferrites, Phys. Rev. vol.99, 1955, pp. 1727.

5. R.C.Mackenzie, Nomenclature in thermal analysis: Part IV, J. Thermal Anal, vol. 13, 1978, pp. 387-392.

6. El-Rafie, Mohamed, Shaheen, Hebeish, "Antimicrobial effect of silver nanoparticles produced by fungal process on cotton fabrics," Carbohydrate Polymers., vol. 80, no.3, 2010, pp. 779-782.

7. Radhai Rajendran, C. Balakumar, J. Kalaivani, R. Sivakumar, "Dyeing and antimicrobial properties of cotton fabrics finished with Punica granatum extracts," J. Text. Appar. Technol. Manag., vol.7, 2011, pp. $1-12$.

8. Ojas Mahapatra, Megha Bhagat, C. Gopalakrishnan \& Kantha D. Arunachalam, "Ultrafine dispersed $\mathrm{CuO}$ nanoparticles and their antibacterial activity," J. Exp Nanosci.,vol.3, 2008, pp.185-193.

9. Nhiem Tran, Aparna Mir, Dhriti Mallik, Arvind Sinha, Suprabha Nayar, and Thomas J Webster, "Bactericidal effects of iron oxide nanoparticles on Staphylococcus aureus," Int J. Nanomedicine., vol.5, 2010, pp. 277-278.

\section{AUTHORS PROFILE}

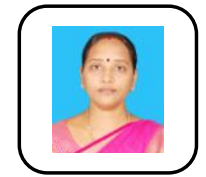

M. S. Revathy, has completed her Ph.D in Anna University in 2016. She has done M.Sc., M.Phil Physics in Mother Teresa Women's University, Kodaikanal. Currently working as Assistant Professor in Department of Physics, Kalasalingam Academy of Research and Education and her field of interests are thin films and green synthesis of nanomaterials. She has published 6 papers in national and international journals.

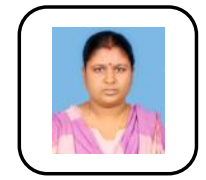

S. R. Chitra, a Research fellow in Thiagarajar College of Engineering, Madurai had fulfilled her $\mathrm{Ph} . \mathrm{D}$ in semiconductor Physics and published seven articles in theoretical physics, seventeen articles in quantum dots, nanoferrites and nano/ferrofluids and two books(Semiconductor Physics and Low Dimensional Semiconductor Physics with ISBN number). These books are intended as a reference book for PG, M.Phil., and Research students in Physics. She has presented seven conference papers about nanomaterials.

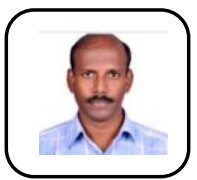

R. Suman has completed B.Sc., M.Sc in Chemistry from Saraswathi Narayanan College, M.Phil at Madurai Kamaraj University, Ph.D in Anna university Chennai. Currently working as Assistant Professor in Francis Xavier Engineering College. His field of interest is solar cell in physical chemistry field. He has published 3 papers in leading International journals.

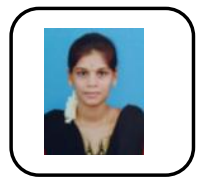

S. Shenbagavalli is currently pursuing as a Research Scholar in Department of Physics, Kalasalingam Academy of Research and Education. Her field of interest is polymer electrolytes.

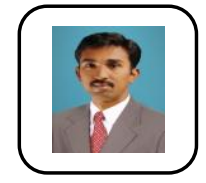

S. Jeyavijayan has completed M.Sc. and Ph.D. from Bharathidasan University, Trichirappalli in 2014 and worked as Assistant Professor in JJ College of Engineering and Technology, Trichy for 10 years. Joined as Assistant Professor at Kalasalingam University from June 2015 onwards. Published more than 25 papers in National and International Journals. His fields of interest are Molecular Spectroscopy and Theoretical and Computational chemistry.

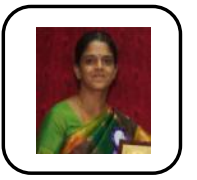

T. Theivashanthi, Assistant Professor in Physics of Kalasalingam University doing research in nanomaterials / nanotechnology; has 15 years of teaching experience; published many research articles/ books. She is a life member of Indian Science Congress Association and Magnetics Society of India; member of International Association of Advanced Materials; serving as Editorial Board Member/ reviewer for some scientific journals; lead editor in JNNN special issue (SAGE Publications, UK); achieved many awards/ honours/ recognitions. She has achieved World Record in LIMCA Book of Records-2015 for nanotechnology invention "World's first superparamagnetic plants materials" - named "Santhi Particles. 